Article

\title{
Concentration and Separation of Heavy Rare-Earth Metals at Stripping Stage
}

\author{
Olga Cheremisina, Vasiliy Sergeev ${ }^{\mathbb{D}}$, Alexander Fedorov * $\mathbb{D}$ and Daria Alferova
}

Department of Physical Chemistry, Faculty of Mineral Processing, Saint Petersburg Mining University, St. Petersburg 199106, Russia; ovcheremisina@yandex.ru (O.C.); sergeev.spmi@yandex.ru (V.S.); alferovadasha@yandex.ru (D.A.)

* Correspondence: bers10@bk.ru; Tel.: +79-046-322-412

Received: 5 November 2019; Accepted: 4 December 2019; Published: 6 December 2019

check for updates

\begin{abstract}
The separation and concentration processes of heavy rare-earth metals-yttrium, ytterbium, erbium, and dysprosium-during stripping from the organic phase based on di-2-ethylhexylphosphoric acid (D2EHPA, or DEHPA) solutions were investigated in this work. Optimal conditions providing high separation factors of rare-earth metals (REM) and their extraction degree to the aqueous phase were determined. The usage of sulfuric acid solutions with a concentration of 2-6 mol/L, depending on the type of extracted rare-earth element, was proposed as a stripping agent for rare-earth metals (REM), and the usage of oxalic acid solution was proposed as an iron stripping solution from the organic phase. To increase the REM stripping efficiency, the antagonistic effect of tributyl phosphate in the di-2-ethylhexylphosphoric acid-kerosene-tributyl phosphate system was considered. The possibility of increasing the capacity of the organic solvent by cleaning the organic phase from iron ions using oxalic acid solutions was revealed. The influence of temperature, aqueous and organic phase ratio, stirring rate, and re-extractant concentration on the distribution and separation factors of adjacent heavy rare-earth-metal (HREM) pairs during the re-extraction process were determined. A schematic diagram of the laboratory-tested separation process of heavy rare-earth metals into individual components with the obtaining of yttrium and ytterbium concentrates containing more than $99 \%$ of the target components was proposed.
\end{abstract}

Keywords: liquid extraction; di-2-ethylhexylphosphoric acid; wet process phosphoric acid; apatite; yttrium; ytterbium; erbium; dysprosium

\section{Introduction}

Apatite ore of the Khibiny deposit of the Murmansk region contains about 1\% rare-earth metals (REM), with a predominant content of medium and heavy rare-earth groups. During the production of phosphate fertilizers by apatite treatment with sulfuric acid, a part of the REM is leached into wet-process phosphoric acid (WPA) [1]. This solution does not require any preliminary treatment (mixing, dissolving, and enrichment), which ensures its potential economic advantages [2]. Furthermore, unlike most phosphorus-containing ores, apatite of the Khibiny deposit does not contain radioactive isotopes of uranium and thorium.

Due to the similarity of chemical properties of yttrium and heavy rare-earth metals, their separation is a complex analytical and technological task. Processes of separation, concentration, and refining of REM are due to the different strengths of the resulting complexes of rare-earth metals with di-2-ethylhexylphosphoric acid (D2EHPA). The larger the charge and the smaller the REM ion radius, the stronger the organic compound with rare-earth metals [3]. 
Extraction methods are widely used to recover individual compounds of rare-earth metals. Rare-earth metals can be extracted by one of three main mechanisms: In the form of solvated salts, chelates with acidic extractants, or ionic couples.

The recovery of rare-earth metals from the products of apatite concentrate processing is conducted from strongly acidic nitrate-phosphate or phosphate-sulphate media, which determines the utilization of mainly acidic organophosphorus and neutral extractants [4-6].

Tributyl phosphate (TBP), Cyanex 272, Cyanex 302, Cyanex 923, di-2-ethylhexylphosphoric acid (DEHPA), dibutylphosphoric acid (DBPA), and diamylphosphoric acid (DAPA) are used as organophosphorus extractants in phosphoric acid systems [7-10].

A classic example of extraction by the mechanism of the formation of chelate complexes with acidic extractants is the extraction by di-2-ethylhexylphosphoric acid, which forms strong complex compounds with rare earths. This feature makes it possible to efficiently carry out extraction-chromatographic separation of rare-earth metals and use mineral inorganic acids- $\mathrm{HCl}, \mathrm{HNO}_{3}$, etc.-as the mobile phase, without using complexing eluents.

On the other hand, the complex salt composition of industrial phosphoric acid solutions with a $\mathrm{pH}$ value of less than 1 and the extremely low concentration of rare-earth metals, especially the heavy group, with respect to impurity components, complicate the process of the separation of rare-earth metals and cause a low capacity of the extractant for individual rare-earth compounds. Particularly noteworthy is the favorable extraction of iron ions (3+) from phosphoric acid solutions with D2EHPA solutions, which, by analogy with REM, form strong chelate complexes [11,12].

Disrupting iron ion (3+) chelate complexes requires the use of concentrated mineral acids, their mixtures, or certain salt solutions with higher displacement capabilities [12].

With the co-extraction of REM during the utilization of concentrated mineral acids, a low efficiency or purification degree of the organic phase from impurities, including iron, are significant drawbacks of acid elution methods [11].

Purification of an organic solution of D2EHPA from iron cations (3+) using different reagents was investigated in $[13,14]$. The authors determined that the effective extraction of iron-about $75 \%$-from the organic phase occurs when using a buffer solution of oxalic acid and ammonium oxalate as a stripping agent.

Akhlaghi et al. investigated the effect of TBP on the iron stripping process and found that an increase in the concentration of the tributyl phosphate in D2EHPA of 2-6\% leads to an increase in the degree of iron stripping from the organic phase [13].

An investigation of the extraction efficiency by different mixtures of organophosphorus acid extractants: Di-(2-ethylhexyl) phosphoric acid-P204, 2-ethylhexyl phosphoric acid mono-2-ethylhexyl ester-P507, di-(2-ethylhexyl) phosphinic acid-P227, and bis (2,4,4-trimethylpentyl) phosphinic acid-Cyanex272, C272, from the chloride medium was carried out by Liu et al. [15]. The authors investigated the extraction and stripping ability of mixtures, their extraction capacity, the equilibrium time, and the separation factors of heavy rare-earth metals. It was revealed that the mixture of P507 and P227 is the most effective among the six mixed systems. This system is characterized by a low stripping acidity, higher load capacity, shorter equilibrium time, and high separation factors of adjacent HREM—yttrium (Y), erbium (Er), thulium $(\mathrm{Tm})$, ytterbium $(\mathrm{Yb})$, and lutetium $(\mathrm{Lu})$.

In [16], Wei et al. investigated the extraction of trivalent rare-earth metals by heptylaminomethyl phosphonic acid 2-ethylhexyl ester (HEHHAP). This extractant showed good performance during extraction from low-acidity mediums, but with an increase in acidity, its effectiveness decreased significantly. Therefore, the considered extractant cannot be used for the effective extraction of rare-earth metals from WPA.

The extraction of rare-earth metals from industrial solutions of acids obtained by processing secondary sources, such as mining waste, was investigated by Tunsu et al. [17]. During this research, extraction from different mineral acids was carried out using solvating (Cyanex 923, TODGA) and acidic (DEHPA, Cyanex 572) extractants. Authors note that the use of acidic extractants for REM recovery 
from acidic media has significant advantages such as a better selectivity and mineral acid range, while solvating extractants give satisfactory results only during extraction from nitric acid. In addition, it is reported that the co-extraction of iron significantly reduces the extraction efficiency. This drawback can be mitigated by several methods: Extraction at non-equilibrium conditions, extraction by a DEHPA and Cyanex 923 mixture-which also leads to a better REM extraction efficiency-and by using nitric acid or diluted hydrochloric acid at the stripping stage.

The co-extraction of neodymium (Nd), boron (B), cobalt ( $\mathrm{Co})$, and iron (Fe) by solutions of DEHPA from citric acid and acetic acid leachate was addressed by Gergoric et al. in [18]. It was found that less than $1 \%$ of $B$ and Co were extracted from leachates by $0.2-1$ mol/L DEHPA solutions. The highest separation factor of the $\mathrm{Fe} / \mathrm{Nd}$ pair of about 161.9 was achieved at $0.2 \mathrm{~mol} / \mathrm{L}$ acetic acid extraction with $1 \mathrm{~mol} / \mathrm{L}$ DEHPA.

In [19], Heres et al. considered a wide range of ion-exchange resins for the extraction of rare-earth metals from phosphoric acid solutions. Considered resins are capable of providing a high extraction efficiency, but significant impurity recovery degrees, as well as low separation factors, make it unacceptable for the current task.

In the technology of rare-earth metals, the choice of extraction systems is determined by the value of the separation factor. With a separation factor value of 1.6-3.5 for the nearest pairs of elements, it is possible to perform an extraction process organized according to a multiple-stage scheme.

The aim of this work is to determine the factors affecting the concentration and separation processes of heavy-group rare-earth metals and to establish the composition of D2EHPA-based extraction systems with the aim of increasing the capacity of the organic phase with respect to rare-earth metals and the degree of purification from iron impurities. Herewith, it is necessary to ensure a minimum change in the composition of the initial industrial phosphoric acid solution, as it will be directed to the production of phosphoric fertilizers.

\section{Materials and Methods}

Phosphoric acid solutions were obtained from PJSC PhosAgro (Balakovo Branch of Apatit, Saratov Region, Balakovo District, Russian) as a product of apatite processing. The composition of industrial phosphoric acid solutions obtained during the sulphuric acid leaching of phosphate ores-WPA-is shown in Tables 1 and 2. Simulated solutions containing $4.5 \mathrm{~mol} / \mathrm{L} \mathrm{H}_{3} \mathrm{PO}_{4}$ (prepared by dilution from concentrated chemical pure grade phosphoric acid, obtained from OOO Komponent-Reaktiv, Moscow, Russian) and $0.19 \mathrm{~mol} / \mathrm{L} \mathrm{H}_{2} \mathrm{SO}_{4}$ were used as an analogue of the industrial wet-process phosphoric acid—WPA—acidic system.

Table 1. Wet-process phosphoric acid (WPA) solution compositions (mass. \%).

\begin{tabular}{cccccccc}
\hline $\mathrm{Ln}$ & $\mathbf{P}_{\mathbf{2}} \mathrm{O}_{5}$ & $\mathrm{SO}_{3}$ & $\mathbf{F}$ & $\mathrm{Al}_{2} \mathbf{O}_{3}$ & $\mathrm{CaO}$ & $\mathrm{Fe}_{2} \mathrm{O}_{3}$ & $\mathrm{SiO}_{2}$ \\
\hline $0.07-0.1$ & $26-28$ & $1.2-1.8$ & $1.4-1.5$ & $0.1-0.4$ & $0.3-0.8$ & $0.3-0.4$ & $0.8-1.1$ \\
\hline
\end{tabular}

Table 2. Relative content of rare-earth metals (REM) oxides $\left(\mathrm{Ln}_{2} \mathrm{O}_{3}\right)$ in WPA solutions.

\begin{tabular}{cccccc}
\hline REM Oxide & Content, $\%$ & REM Oxide & Content, $\%$ & REM Oxide & Content, $\%$ \\
\hline $\mathrm{La}_{2} \mathrm{O}_{3}$ & 15.070 & $\mathrm{Sm}_{2} \mathrm{O}_{3}$ & 3.175 & $\mathrm{Dy}_{2} \mathrm{O}_{3}$ & 1.920 \\
$\mathrm{Ce}_{2} \mathrm{O}_{3}$ & 37.540 & $\mathrm{Eu}_{2} \mathrm{O}_{3}$ & 0.960 & $\mathrm{Yb}_{2} \mathrm{O}_{3}$ & 0.510 \\
$\mathrm{Pr}_{2} \mathrm{O}_{3}$ & 4.670 & $\mathrm{Gd}_{2} \mathrm{O}_{3}$ & 3.510 & $\mathrm{Y}_{2} \mathrm{O}_{3}$ & 12.83 \\
$\mathrm{Nd}_{2} \mathrm{O}_{3}$ & 18.34 & $\mathrm{~Tb}_{2} \mathrm{O}_{3}$ & 0.425 & $\mathrm{Er}_{2} \mathrm{O}_{3}$ & 0.880 \\
\hline
\end{tabular}

We used organic phases based on mixtures of di-2-ethylhexylphosphoric acid produced by "Acros Organics" (obtained from ZAO Acrus, Moscow, Russian), with a D2EHPA concentration of at least $95 \%$, with inert diluent "pure" grade kerosene with a mass fraction of saturated hydrocarbons of at 
least 95\%, and tributyl phosphate, produced by "Acros Organics" (obtained from ZAO Acrus, Moscow, Russia), with a $99 \%$ TBP content.

Solutions of sulphuric and oxalic acids were obtained by diluting concentrated (94\%) sulphuric acid and dissolving "chemically pure" grade oxalic acid in an appropriate volume of water, used as a stripping agent.

The experimental research of REM stripping was carried out in two different types of reactors. The HEL Group AutoLAB chemical reactor (HEL Ltd, Borehamwood, UK) equipped with a submersible stirrer, was used to treat the mixture of water and organic phases with a total volume of up to $1 \mathrm{~L}$, and the HEL Group Automate Parallel Chemistry reactor (HEL Ltd, Borehamwood, UK), equipped with a magnetic stirrer, was used for carrying multiple extraction experiments under mixtures of water and organic phases with a total volume of up to $0.2 \mathrm{~L}$. Both reactors are suitable for controlling the following process parameters: Temperature, phase contact period, stirring rate, and system acidity level.

Quantitative analysis of the organic and aqueous phase samples was carried out using a spectrophotometric method with Arsenazo (III) and a PANalytical Epsilon 3 X-ray fluorescence energy-dispersive spectrometer (obtained from OOO KD Sistemy i Oborudovaniye, St. Petersburg, Russian) with a sensitivity threshold of $10^{-4} \mathrm{~mol} / \mathrm{L}$ and a measurement error of less than $5 \%$. To ensure the reliability of the obtained results, the samples were measured several times.

\section{Results}

\subsection{Stripping Agent Concentration Effect on Separation Factors of REM Heavy Group}

The study was undertaken using solutions with a D2EHPA volume fraction of 0.3 diluted with kerosene, obtained after extraction of a collective mixture or individual REM from the simulated solution, similar to WPA in the phosphoric and sulphuric acid composition.

Disrupting the organic extractant complex with REM ions and, accordingly, their isolation from the organic phase into stripped solution is ensured by the use of high-concentration mineral acids. Sulphuric acid is an optimal stripping agent as it is already used as a leaching agent for apatite concentrate; moreover, sulphuric acid is also an affordable and relatively inexpensive reagent.

The organic phase, containing a certain amount of individual REM, was treated in a Parallel Automated H.E.L. reactor (HEL Ltd, Borehamwood, UK) under a temperature of $295 \mathrm{~K}$, stirring rate of $450 \mathrm{~min}^{-1}$, aqueous-to-organic phase ratio of 2:1, and five minutes of phase contact period, which exceeds the time to reach equilibrium, which was about $2-3 \mathrm{~min}$. The initial $\left(C_{0}(\mathrm{Ln})_{\text {org }}\right)$ and equilibrium $\left(C_{\infty}(\mathrm{Ln})\right)$ concentrations of erbium, yttrium, dysprosium, and ytterbium and the stripping degree $(E$, $\%)$ are shown in Tables 3 and 4.

Table 3. Experimental data on erbium and yttrium stripping.

\begin{tabular}{|c|c|c|c|c|c|c|c|c|}
\hline $\begin{array}{c}C\left(\mathrm{H}_{2} \mathrm{SO}_{4}\right) \\
\mathrm{mol} / \mathrm{L}\end{array}$ & $\begin{array}{c}C_{0}(\mathrm{Er})_{\text {org }} \\
\mathrm{mmol} / \mathrm{L}\end{array}$ & $\begin{array}{c}C_{\infty}(\mathrm{Er})_{\mathrm{aq}}{ }^{\prime} \\
\mathrm{mmol} / \mathrm{L}\end{array}$ & $\begin{array}{c}C_{\infty}(\mathrm{Er})_{\text {org }} \\
\mathrm{mmol} / \mathrm{L}\end{array}$ & $\begin{array}{l}E, \\
\%\end{array}$ & $\begin{array}{l}C_{0}(\mathrm{Y})_{\mathrm{org}} \\
\mathrm{mmol} / \mathrm{L}\end{array}$ & $\begin{array}{c}C_{\infty}(\mathrm{Y})_{\mathrm{org}} \\
\mathrm{mmol} / \mathrm{L}\end{array}$ & $\begin{array}{l}C_{\infty}(\mathrm{Y})_{\mathrm{aq}}{ } \\
\mathrm{mmol} / \mathrm{L}\end{array}$ & $\begin{array}{l}E, \\
\%\end{array}$ \\
\hline 6.0 & 6.13 & 11.46 & 0.40 & 93.47 & 10.58 & 0.30 & 20.76 & 98.11 \\
\hline 4.5 & 6.13 & 10.50 & 0.88 & 85.64 & 10.58 & 1.26 & 18.64 & 88.09 \\
\hline 3.0 & 6.13 & 5.30 & 3.48 & 43.23 & 10.58 & 4.57 & 12.02 & 56.81 \\
\hline 2.0 & 6.13 & 2.36 & 4.95 & 19.25 & 9.55 & 6.68 & 5.74 & 30.05 \\
\hline 1.0 & 6.13 & 0.12 & 6.07 & 0.98 & 9.55 & 9.30 & 0.50 & 2.62 \\
\hline
\end{tabular}

Table 4. Experimental data on dysprosium and ytterbium stripping.

\begin{tabular}{|c|c|c|c|c|c|c|c|c|}
\hline $\begin{array}{c}\mathrm{C}\left(\mathrm{H}_{2} \mathrm{SO}_{4}\right) \\
\mathrm{mol} / \mathrm{L}\end{array}$ & $\begin{array}{c}C_{0}(\mathrm{Dy})_{\text {org}} \\
\mathrm{mmol} / \mathrm{L}\end{array}$ & $\begin{array}{c}C_{\infty}(\mathrm{Dy})_{\mathrm{aq}}, \\
\mathrm{mmol} / \mathrm{L}\end{array}$ & $\begin{array}{c}C_{\infty}(\text { Dy) org, } \\
\mathrm{mmol} / \mathrm{L}\end{array}$ & $\begin{array}{l}E, \\
\%\end{array}$ & $\begin{array}{c}C_{0}(\mathrm{Yb})_{\text {org }} \\
\mathrm{mmol} / \mathrm{L}\end{array}$ & $\begin{array}{c}C_{\infty}(\mathrm{Yb})_{\mathrm{aq}}, \\
\mathrm{mmol} / \mathrm{L}\end{array}$ & $\begin{array}{c}C_{\infty}(\mathrm{Yb})_{\text {org }} \\
\mathrm{mmol} / \mathrm{L}\end{array}$ & $\begin{array}{l}E, \\
\%\end{array}$ \\
\hline 6.0 & 3.98 & 7.93 & 0.02 & 99.62 & 12.75 & 15.82 & 4.84 & 62.04 \\
\hline 4.5 & 3.98 & 7.76 & 0.10 & 97.49 & 12.75 & 8.44 & 8.53 & 33.10 \\
\hline 3.0 & 4.13 & 6.40 & 0.93 & 77.48 & 12.75 & 2.72 & 11.39 & 10.67 \\
\hline 2.0 & 3.98 & 5.76 & 1.10 & 72.36 & 11.49 & 0.98 & 11.00 & 4.26 \\
\hline 1.0 & 3.98 & 1.52 & 3.22 & 19.10 & 11.49 & 0.20 & 11.39 & 0.87 \\
\hline
\end{tabular}


Naturally, with the increase in sulphuric acid concentration, the extraction degree of REM from the organic phase to the stripped solution increases. However, due to the different stability of rare-earth-metal solvate complexes with D2EHPA using sulphuric acid of the same composition, different values of the individual rare-earth-metal extraction degree are observed, which are proportional to the distribution coefficients of REM during stripping (Table 5).

Table 5. Values of rare-earth metal distribution coefficients between aqueous and organic phases.

\begin{tabular}{ccccc}
\hline \multirow{2}{*}{$\mathbf{C}\left(\mathbf{H}_{\mathbf{2}} \mathbf{S O}_{\mathbf{4}}\right), \mathbf{m o l} / \mathbf{L}$} & $\mathbf{D y}$ & $\mathbf{Y}$ & $\mathbf{E r}$ & $\mathbf{Y b}$ \\
\hline 6.0 & 328.67 & 36.80 & 28.65 & 3.27 \\
4.5 & 77.60 & 14.79 & 11.93 & 0.99 \\
3.0 & 6.88 & 2.63 & 1.52 & 0.24 \\
2.0 & 5.24 & 0.86 & 0.48 & 0.09 \\
1.0 & 0.47 & 0.05 & 0.02 & 0.02 \\
\hline
\end{tabular}

The lowest distribution coefficients between the aqueous and organic phases are observed for ytterbium, which is most efficiently extracted from phosphoric acid solutions and forms more stable complexes with D2EHPA [11,15]. For example, using a 50\% solution of D2EHPA in kerosene with an aqueous-to-organic phase ratio $V_{a q} / V_{\text {org }}=10$, the extraction degree average values after 10 stages of extraction are $3 \%$ for yttrium (Y), $5 \%$ for erbium (Er), $1 \%$ for dysprosium (Dy), and $45 \%$ for ytterbium $(\mathrm{Yb})$.

Therefore, a decrease in the extraction degree of rare-earth metals into the aqueous phase in the series dysprosium $(\mathrm{Dy})>$ yttrium $(\mathrm{Y})>$ erbium $(\mathrm{Er})>$ ytterbium $(\mathrm{Yb})$ causes different stabilities of the rare-earth-metal solvate complexes with D2EHPA in the organic phase, which may be the reason for the effective separation of rare-earth metals at the stripping stage. The values of the separation factors $(\beta)$ of individual REM are shown in Table 6.

Table 6. Values of the separation factors $(\beta)$ between REM on the stripping stage, using sulphuric acid solutions.

\begin{tabular}{ccccccc}
\hline \multirow{2}{*}{$\begin{array}{c}C\left(\mathrm{H}_{\mathbf{2}} \mathrm{SO}_{4}\right), \\
\mathbf{m o l} / \mathrm{L}\end{array}$} & $\boldsymbol{\beta}(\mathrm{Dy} / \mathrm{Y})$ & $\boldsymbol{\beta}(\mathrm{Y} / \mathrm{Er})$ & $\boldsymbol{\beta}(\mathbf{E r} / \mathrm{Yb})$ & $\boldsymbol{\beta}(\mathrm{Dy} / \mathrm{Yb})$ & $\boldsymbol{\beta}(\mathbf{Y} / \mathbf{Y b})$ & $\boldsymbol{\beta}$ (Dy/Er) \\
\cline { 2 - 7 } & 9.06 & 1.28 & 8.77 & 161.74 & 11.3 & 18.45 \\
6.0 & 5.25 & 1.24 & 12.06 & 78.43 & 14.95 & 6.50 \\
4.5 & 2.62 & 1.73 & 6.38 & 28.82 & 11.01 & 4.52 \\
3.0 & 6.08 & 1.80 & 5.35 & 58.78 & 9.64 & 10.98 \\
2.0 & 8.70 & 2.72 & 1.13 & 26.88 & 3.06 & 23.88 \\
1.0 & & & & & & \\
\hline
\end{tabular}

According to the experimental data obtained, the separation of dysprosium/erbium and dysprosium/ytterbium pairs is the most effective in the stripping stage. A comparison of the obtained separation factors with previously published data $[3,14,15]$ is given in Table 7 .

Table 7. Comparison of separation factors.

\begin{tabular}{|c|c|c|c|c|c|c|c|}
\hline \multirow{2}{*}{ Paper } & \multicolumn{6}{|c|}{ Separation Factors $(\beta)$} & \multirow{2}{*}{ Method } \\
\hline & $\beta(\mathrm{Dy} / \mathrm{Y})$ & $\beta(\mathrm{Y} / \mathrm{Er})$ & $\beta(\mathrm{Er} / \mathrm{Yb})$ & $\beta(\mathrm{Dy} / \mathrm{Yb})$ & $\beta(\mathrm{Y} / \mathrm{Yb})$ & $\beta$ (Dy/Er) & \\
\hline Current & 9.06 & 2.72 & 12.06 & 161.74 & 14.95 & 23.88 & Stripping \\
\hline Liu et al. [14] & - & 1.47 & 9.18 & - & 15.01 & - & Extraction \\
\hline Wei et al. [15] & 1.19 & 2.18 & 6.83 & 17.8 & 14.9 & 2.6 & Extraction \\
\hline Cheremisina et al. [3] & 6.45 & 1.7 & 23 & 161 & $8-36$ & 4 & Extraction \\
\hline
\end{tabular}


The lowest separation factors were obtained for erbium and yttrium; however, given the quantitative advantage of yttrium in WPA solutions relative to erbium, it is possible to obtain yttrium concentrate with a high content of the target component.

Thus, for the effective separation of heavy REM and their maximum concentration at the stripping stage, it is advisable to use sulphuric acid solutions with an $\mathrm{H}_{2} \mathrm{SO}_{4}$ content higher than $4 \mathrm{~mol} / \mathrm{L}$.

\subsection{Effect of Phase Stirring Rate on Heavy Group of REM Stripping Efficiency}

The influence of the phase stirring rate on the quantitative indicators of stripping was studied using a simulated phosphoric acid solution with a D2EHPA volume fraction of 0.3 diluted with kerosene, and the content of individual rare-earth metals was as follows: ytterbium $(\mathrm{Yb})$, yttrium $(\mathrm{Y})$, and erbium (Er) with organic-to-aqueous phase ratio equal to ten, phase contact time of five minutes, and concentration of stripping agent $C\left(\mathrm{H}_{2} \mathrm{SO}_{4}\right)=6 \mathrm{~mol} / \mathrm{L}$.

Experimental results are shown in Table 8 and Figure 1, which show the dependence of the extraction degree of metals into the aqueous phase on the phase stirring rate.

Table 8. Distribution coefficients $(D)$ at different phase stirring rates.

\begin{tabular}{|c|c|c|c|c|}
\hline$C_{0}(\mathrm{Yb})_{\mathrm{org}}, \mathrm{mmol} / \mathrm{L}$ & $C_{\infty}(\mathrm{Yb})_{\mathrm{aq}}, \mathrm{mmol} / \mathrm{L}$ & $C_{\infty}(\mathrm{Yb})_{\mathrm{org}}, \mathrm{mmol} / \mathrm{L}$ & $D$ & Stirring Rate, $\mathrm{min}^{-1}$ \\
\hline 2.45 & 4.7 & 1.98 & 2.37 & 300 \\
\hline 2.45 & 4.8 & 1.97 & 2.44 & 400 \\
\hline 2.45 & 9.2 & 1.53 & 6.01 & 450 \\
\hline 2.45 & 7.4 & 1.71 & 4.33 & 500 \\
\hline 2.45 & 6.8 & 1.77 & 3.84 & 600 \\
\hline$C_{0}(\mathrm{Y})_{\text {org }}, \mathrm{mmol} / \mathrm{L}$ & $C_{\infty}(\mathrm{Y})_{\mathrm{aq}}, \mathrm{mmol} / \mathrm{L}$ & $C_{\infty}(\mathrm{Y})_{\text {org }}, \mathrm{mmol} / \mathrm{L}$ & $D$ & Stirring Rate, $\min ^{-1}$ \\
\hline 18.16 & 107.8 & 7.38 & 14.61 & 300 \\
\hline 18.16 & 136.8 & 4.48 & 30.54 & 400 \\
\hline 18.16 & 159.4 & 2.22 & 71.80 & 450 \\
\hline 18.16 & 149.3 & 3.23 & 46.22 & 500 \\
\hline 18.16 & 157.1 & 2.45 & 64.12 & 600 \\
\hline$C_{0}(\mathrm{Er})_{\text {org }}, \mathrm{mmol} / \mathrm{L}$ & $C_{\infty}(\mathrm{Er})_{\mathrm{aq}}, \mathrm{mmol} / \mathrm{L}$ & $C_{\infty}(\mathrm{Er})_{\mathrm{org}}, \mathrm{mmol} / \mathrm{L}$ & $D$ & Stirring Rate, $\min ^{-1}$ \\
\hline 16.46 & 97.1 & 6.75 & 14.39 & 300 \\
\hline 16.46 & 120.2 & 4.44 & 27.07 & 400 \\
\hline 16.46 & 142.5 & 2.21 & 64.48 & 450 \\
\hline 16.46 & 134.2 & 3.04 & 44.14 & 500 \\
\hline 16.46 & 139.2 & 2.54 & 54.80 & 600 \\
\hline
\end{tabular}

According to obtained dependence, the maximum degree of stripping is observed at $450 \mathrm{~min}^{-1}$, and further increases in the stirring rate is inadvisable. The optimal mode of the stripping process, as well as the extracting process, is determined by the nature of limiting stages, among which mass transfer is related to stirring conditions. At sufficiently high mixing speeds (above $450 \mathrm{~min}^{-1}$ ) in the systems under study, the chemical stage associated with the destruction of the strong solvate complexes of rare-earth metals with D2EHPA and the formation of acidic complexes of REM in aqueous solutions can become a limiting one.

The increase in the distribution coefficients of all REM with an increase in stirring rate up to $450 \mathrm{~min}^{-1}$ is explained by the increase in the interface surface due to the decrease in the heterogeneous phase droplet average size and, consequently, the increase in the mass transfer rate.

With further increases in the stirring rate, the dispersed phase droplet size decreases, resulting in a reduction in liquid circulation within the droplet. The droplets become hard spheres, which leads to a decrease in the mass transfer coefficient as a result of the relatively slow molecular diffusion process at stirring rates above $450 \mathrm{~min}^{-1}$. 


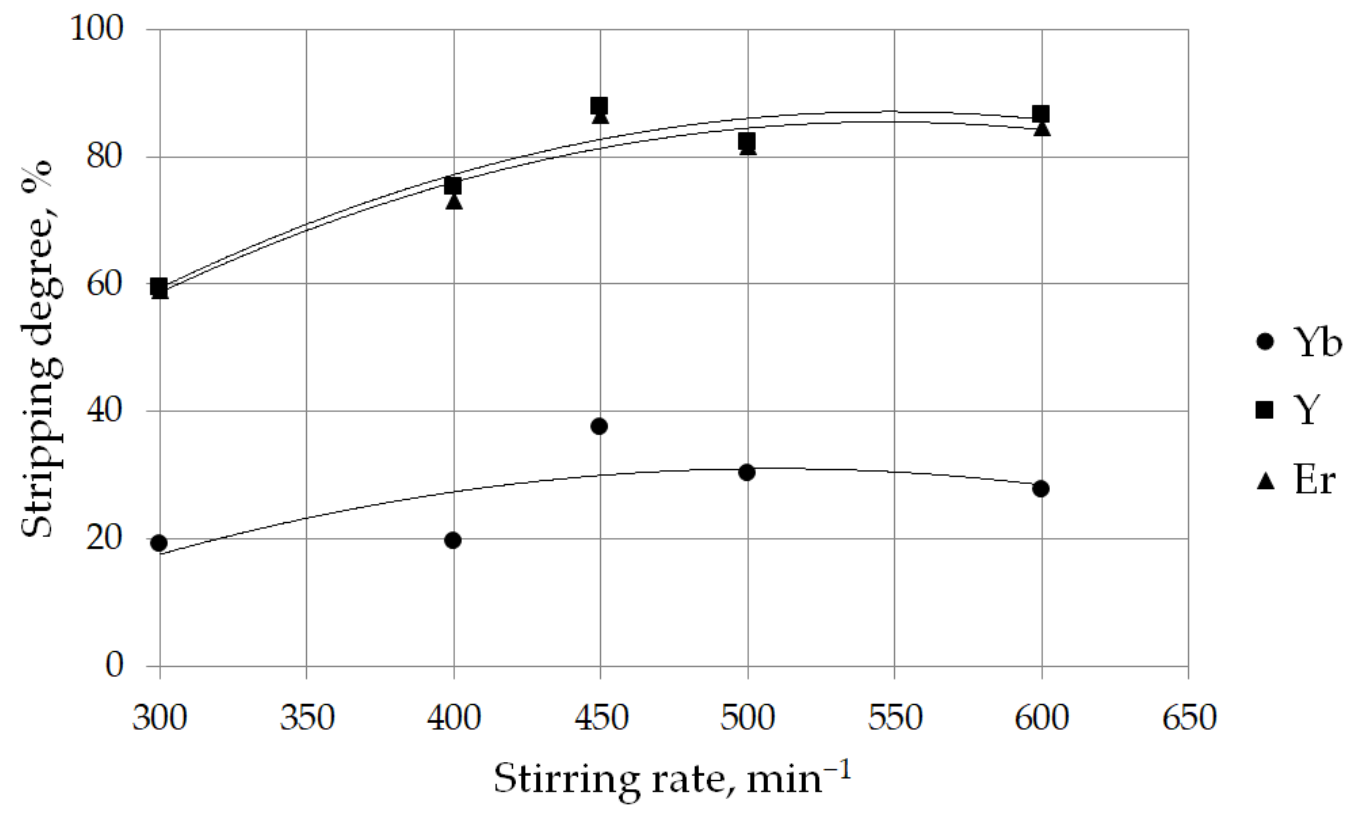

Figure 1. Dependence of the extraction degree of yttrium, ytterbium, and erbium into the aqueous phase on the phase stirring rate under $295 \mathrm{~K}$, phase ratio $V_{\text {org }} / V_{a q}=10$, and $\mathrm{H}_{2} \mathrm{SO}_{4}$ concentration of $6 \mathrm{~mol} / \mathrm{L}$.

\subsection{Temperature Effect on the REM Stripping Degree}

The temperature effect on the stripping degree of yttrium, ytterbium, and erbium from the organic phase was studied with a phase volumes ratio of 1:1, a phase contact time of $5 \mathrm{~min}$, and a stirring rate of $450 \mathrm{~min}^{-1}$ by a solution of sulphuric acid with a concentration of $3 \mathrm{~mol} / \mathrm{L}$. According to the results presented in Figure 2, an increase in temperature from 25 to $60^{\circ} \mathrm{C}$ leads to an increase in the yttrium extraction degree by more than two times, and erbium and ytterbium by more than five.

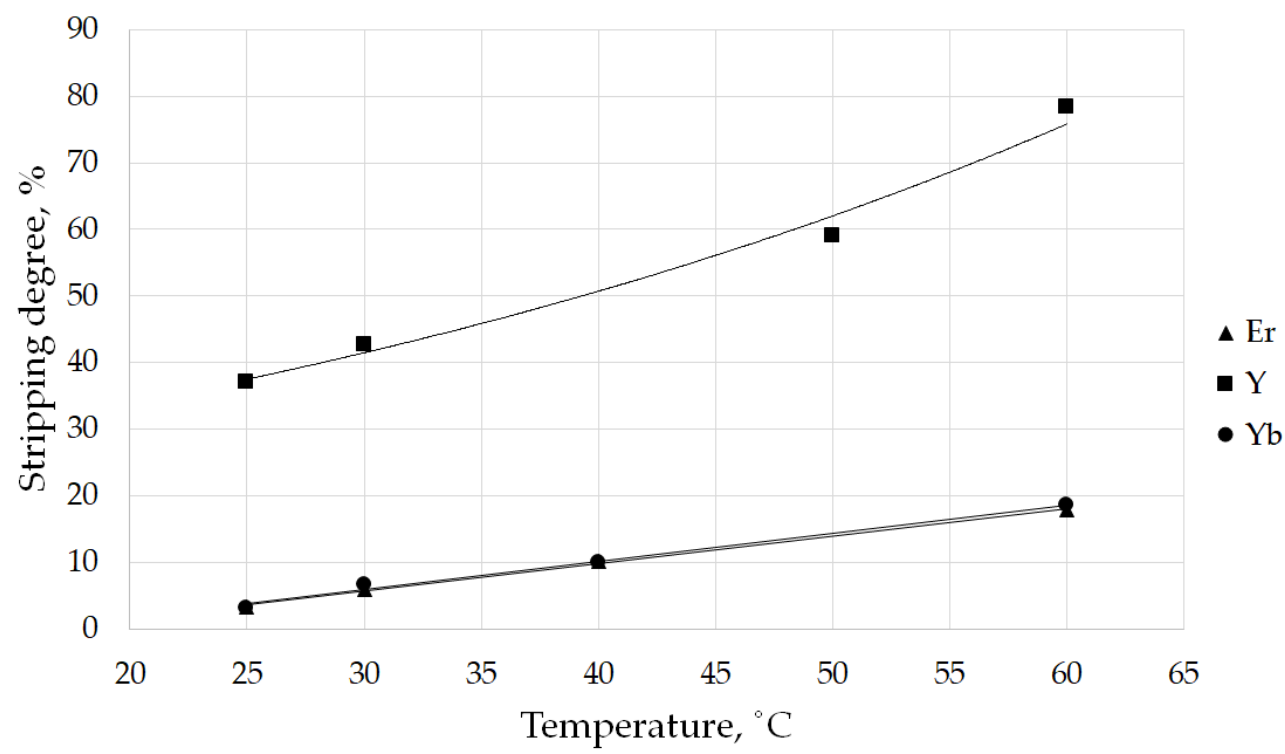

Figure 2. Dependence of the rare-earth metals (REM) extraction degree on temperature.

With increasing temperature, the solubility of lanthanide sulphates in the aqueous phase increase, and the viscosity of the organic phase decreases, which affects the change in the distribution constant of stripped rare-earth metals and leads to an increase in the extraction degree of REM from the organic 
phase. An opposite effect of the decrease in the REM extraction degree with the increase in temperature was observed during the extraction using D2EHPA.

\subsection{Effect of Phase Ratio on Heavy Group of REM Stripping Efficiency}

The phase ratio effect on the ytterbium $(\mathrm{Yb})$, yttrium $(\mathrm{Y})$, and erbium $(\mathrm{Er})$ stripping process was studied using a solution of D2EHPA with a volume fraction of 0.3 diluted with kerosene under the following conditions: Sulphuric acid concentration of $6 \mathrm{~mol} / \mathrm{L}$, stirring rate of $450 \mathrm{~min}^{-1}$, and phase contact time of $5 \mathrm{~min}$. Experimental results are presented in Table 9 and Figure 3.

Table 9. Stripping results under various phases ratios.

\begin{tabular}{|c|c|c|c|c|c|}
\hline$C_{0}(\mathrm{Yb})_{\text {org }}, \mathrm{mmol} / \mathrm{L}$ & $C_{\infty}(\mathrm{Yb})_{\text {org }}, \mathrm{mmol} / \mathrm{L}$ & $C_{\infty}(\mathrm{Yb})_{\mathrm{aq}}, \mathrm{mmol} / \mathrm{L}$ & $E, \%$ & $D$ & $V_{a q} / V_{\text {org }}$ \\
\hline 3.24 & 1.03 & 4.20 & 68.2 & 4.29 & 0.5 \\
\hline 3.24 & 1.97 & 6.35 & 39.2 & 3.22 & 0.2 \\
\hline 3.24 & 2.56 & 6.80 & 20.9 & 2.66 & 0.1 \\
\hline 3.24 & 2.85 & 5.85 & 12.0 & 2.05 & 0.066 \\
\hline 3.24 & 2.96 & 5.60 & 8.6 & 1.89 & 0.05 \\
\hline 3.24 & 3.03 & 6.30 & 6.4 & 2.08 & 0.033 \\
\hline$C_{0}(\mathrm{Y})_{\mathrm{org}}, \mathrm{mmol} / \mathrm{L}$ & $C_{\infty}(\mathrm{Y})_{\mathrm{aq}}, \mathrm{mmol} / \mathrm{L}$ & $C_{\infty}(\mathrm{Y})_{\text {org }}, \mathrm{mmol} / \mathrm{L}$ & $E, \%$ & $D$ & $V_{\text {aq }} / V_{\text {org }}$ \\
\hline 3.67 & 7.32 & 0.01 & 99.73 & $>100$ & 0.5 \\
\hline 3.67 & 17.05 & 0.26 & 92.92 & 65.58 & 0.2 \\
\hline 3.67 & 31.80 & 0.49 & 86.65 & 64.90 & 0.1 \\
\hline 3.67 & 35.25 & 1.32 & 64.03 & 26.70 & 0.066 \\
\hline 3.67 & 39.40 & 1.70 & 53.68 & 23.18 & 0.05 \\
\hline 3.67 & 43.50 & 2.22 & 39.51 & 19.59 & 0.033 \\
\hline$C_{0}(\mathrm{Er})_{\mathrm{org}}, \mathrm{mmol} / \mathrm{L}$ & $C_{\infty}(\mathrm{Er})_{\mathrm{aq}}, \mathrm{mmol} / \mathrm{L}$ & $C_{\infty}(\mathrm{Er})_{\mathrm{org}}, \mathrm{mmol} / \mathrm{L}$ & $E, \%$ & $D$ & $V_{\text {aq }} / V_{\text {org }}$ \\
\hline 1.22 & 0.242 & 0.001 & 99.18 & $>100$ & 0.5 \\
\hline 1.22 & 0.555 & 0.011 & 90.98 & 50.45 & 0.2 \\
\hline 1.22 & 0.970 & 0.025 & 79.51 & 38.80 & 0.1 \\
\hline 1.22 & 0.960 & 0.058 & 52.46 & 16.55 & 0.066 \\
\hline 1.22 & 0.840 & 0.080 & 34.43 & 10.50 & 0.05 \\
\hline 1.22 & 0.750 & 0.097 & 20.49 & 7.73 & 0.034 \\
\hline
\end{tabular}

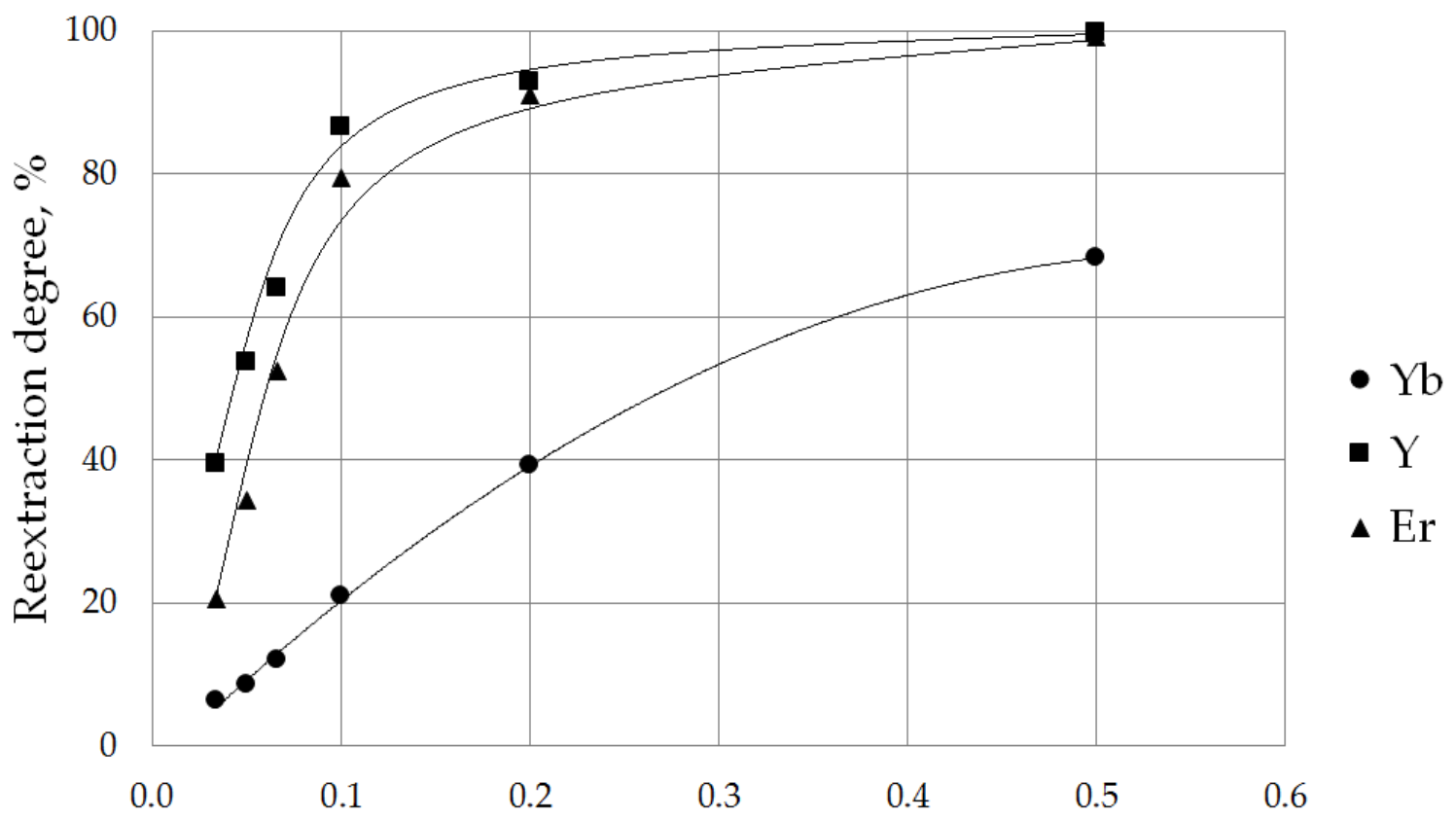

Aqueous to organic phases ratio, Vaq/Vorg

Figure 3. Dependence of the REM stripping degree from organic phase on the phase ratio $(6 \mathrm{~mol} / \mathrm{L}$ $\mathrm{H}_{2} \mathrm{SO}_{4}, 295 \mathrm{~K}, 450 \mathrm{~min}^{-1}$ ). 
It was found that at a $V_{a q} / V_{\text {org }}$ phase ratio above 0.2 , the stripping degree of yttrium and erbium is more than $90 \%$, while with the increase in the volume of the organic phase, a decrease in the distribution coefficients of REM into the organic phase is observed. Obviously, an increase in aqueous phase volume leads to an extraction equilibrium shift to the reaction products side, or rather, to the REM stripping side by sulphuric acid.

The highest quantitative indicators of the stripping process by sulphuric acid with a concentration of $6 \mathrm{~mol} / \mathrm{L}$ was achieved with a phase ratio of $1 / 10$ and $1 / 20$ and a stirring speed of $450 \mathrm{rpm}$.

\subsection{Effect of Neutral Extractant Addition on REM Stripping from D2EHPA-Based Organic Phase}

To identify the antagonistic or antisynergetic effect of the process of REM stripping from the organic phase, a neutral extractant tributyl phosphate was added to the D2EHPA solution (in the absence of kerosene) saturated with ytterbium to obtain TBP solutions with volume fractions of $4 \%$, $6 \%, 10 \%$, and $20 \%$.

Stripping was carried out by sulphuric acid at a concentration of $6 \mathrm{~mol} / \mathrm{L}$ during five minutes under a stirring rate of $450 \mathrm{~min}^{-1}$ and phase ratio of 1:1. Experimental results are presented in Table 10 and Figure 4.

Table 10. Stripping degrees and values of initial and equilibrium concentrations of ytterbium in organic phase.

\begin{tabular}{cccc}
\hline TBP Content in Organic Phase, vol. $\%$ & $\boldsymbol{C}_{\mathbf{0}}(\mathbf{Y b})_{\text {org }}, \mathbf{m m o l} / \mathbf{L}$ & $\boldsymbol{C}_{\infty}(\mathbf{Y b})_{\text {org }}, \mathbf{m m o l} / \mathbf{L}$ & $E_{\boldsymbol{\prime}} \mathbf{\%}$ \\
\hline 0 & 3.24 & 1.29 & $60.2 \%$ \\
4 & 7.75 & 1.49 & $80.7 \%$ \\
6 & 4.27 & 0.61 & $85.7 \%$ \\
10 & 9.82 & 1.01 & $89.7 \%$ \\
20 & 8.73 & 0.23 & $97.4 \%$ \\
\hline
\end{tabular}

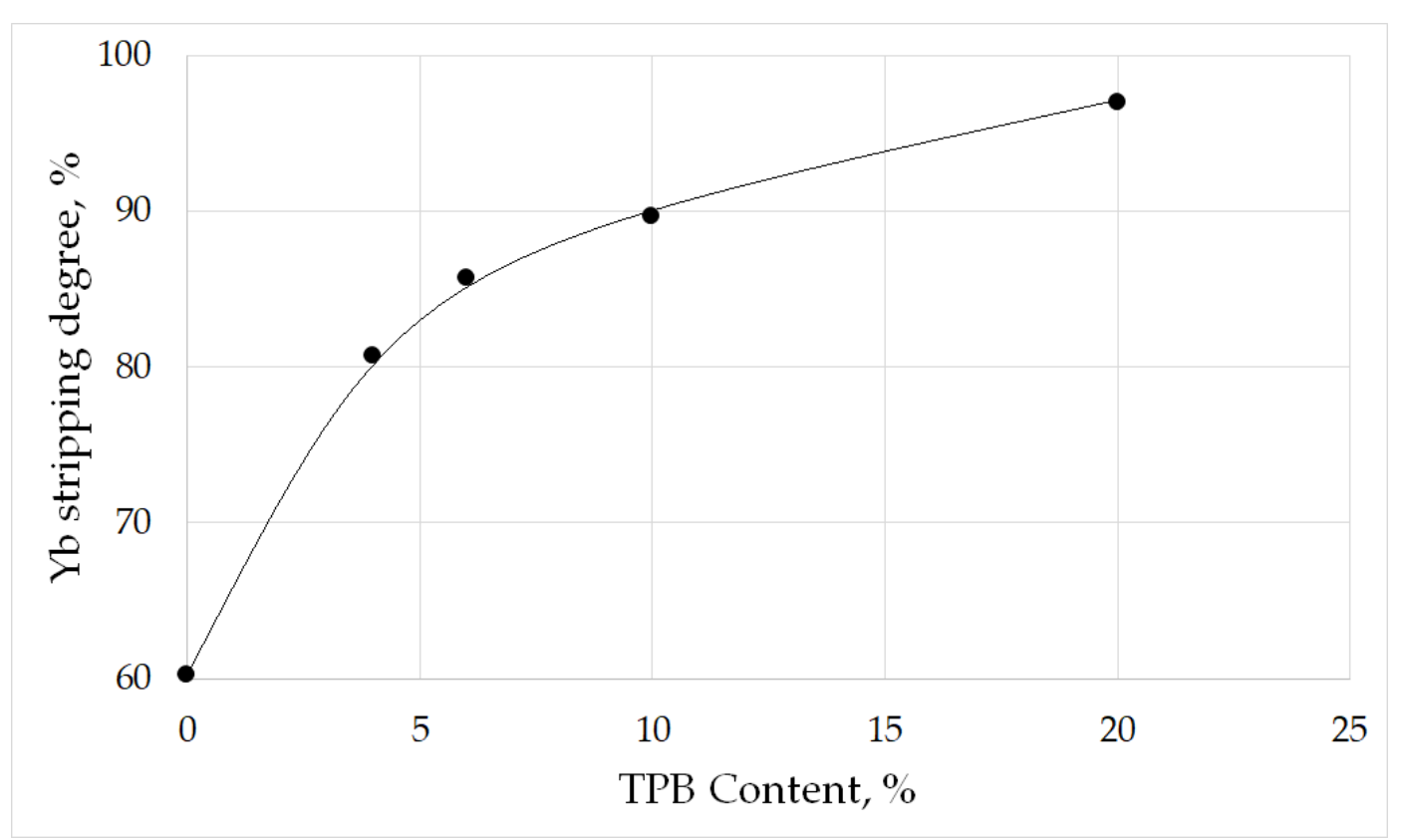

Figure 4. Dependence of the ytterbium stripping degree on volume fraction of tributyl phosphate (TBP) in organic phase.

According to the obtained experimental data, with an increase in TBP volume fraction, the degree of ytterbium stripping degree increases up to $96-98 \%$.

It is unlikely that when salt-forming and neutral extractants are used in the organic phase, the solvate-bounded molecules of one extractant are substituted by the molecules of another. In this case, 
D2EHPA molecules would be isolated from solvate complexes, which is a more effective extractant for REM in comparison with TBP. The reason cannot be the displacement of solvate-bound water by neutral extractant molecules, which would increase the extractability of rare-earth metal complexes.

The antagonistic effect is more likely attributed to intermolecular interactions between organic extractants, leading to the formation of molecular compounds of the n.(D2EHPA).TBP composition, the formation of which is accompanied by the release of inorganic acid complexes of rare-earth metals to the aqueous phase.

\subsection{REM Purification, Concentration, and Separation into Individual Components during Stripping Stage}

REM stripping from the organic phase, obtained during the processing of technological WPA by a solution of D2EHPA diluted with kerosene (1:1), containing $62.78 \%$ of iron (Fe), $28.19 \%$ of yttrium $(\mathrm{Y})$, $3.5 \%$ of erbium $(\mathrm{Er})$, and $5.53 \%$ of ytterbium $(\mathrm{Yb})$, was carried out in several stages. In the first stage, an extract enriched with iron cations $(3+)$ was treated with a solution of oxalic acid at a concentration of $0.37 \mathrm{~mol} / \mathrm{L}$ for $15 \mathrm{~min}$ at a volume ratio of the organic and aqueous phases of $1: 4$ and a stirring rate of $450 \mathrm{~min}^{-1}$.

To extract yttrium from the organic phase, sulphuric acid with a concentration of $2.5-4 \mathrm{~mol} / \mathrm{L}$ was added to the extract, purified from iron. The choice of sulphuric acid concentration was to ensure conditions that prevent the ytterbium stripping. To achieve the most complete yttrium extraction degree, the stripped solution was processed in 14 stages. Control of the organic phase for the yttrium content was carried out throughout all stages of stripping.

Further, in order to increase the ytterbium stripping degree, TBP was added into the organic phase until it reached a volume fraction of 0.2. In order to ensure a high ytterbium stripping degree, a sulphuric acid solution with a concentration of $6 \mathrm{~mol} / \mathrm{L}$ under an organic-to-aqueous phase ratio of 4:1 was used. The obtained mixture of phases was stirred for five minutes under a stirring rate of $450 \mathrm{~min}^{-1}$. The total stripping stages of iron ions (3+) and REM was 22. The technological parameters of the experiment, the characteristics of the stripping agent, and the initial and final concentrations of the components in the organic phase, expressed in $\mathrm{mmol} / \mathrm{L}$, are presented in Table 11.

The dependence of the stripping degree of the target components and iron (3+) on the number of stripping stages is presented in Figure 5.

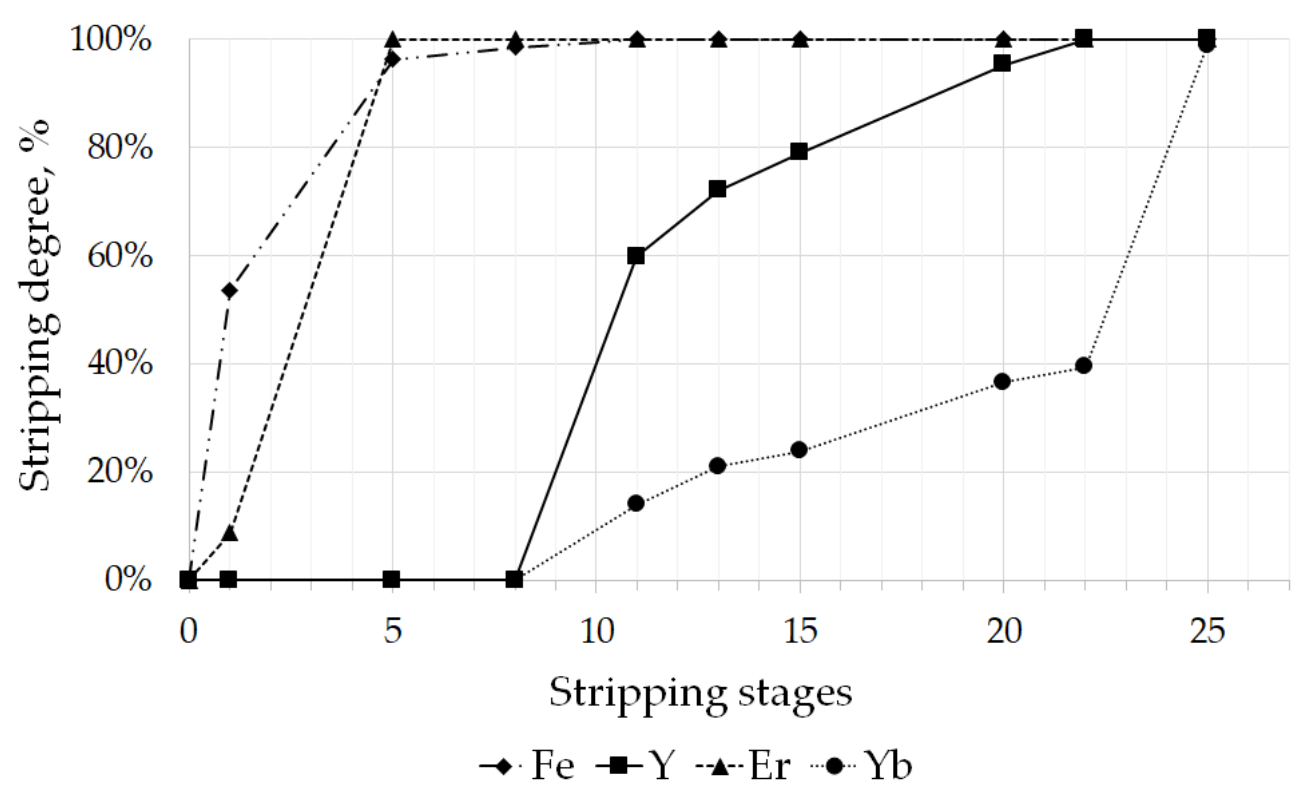

Figure 5. Dependence of the stripping degree of the rare-earth metals and iron on the number of stripping stages. 
Table 11. Technological parameters of experiment and characteristics of re-extractants used.

\begin{tabular}{cccccccccccc}
\hline $\begin{array}{c}\text { Stripping } \\
\text { Stage Number }\end{array}$ & $\begin{array}{c}\text { Stripping } \\
\text { Agent, mmol/L }\end{array}$ & $V_{\text {aq }} / V_{\text {org }}$ & $\boldsymbol{t}, \mathbf{m i n}$ & $\boldsymbol{C}_{\boldsymbol{o}}(\mathrm{Fe})$ & $\boldsymbol{C}_{\infty}(\mathrm{Fe})$ & $\boldsymbol{C}_{\boldsymbol{o}}(\mathrm{Y})$ & $\boldsymbol{C}_{\infty}(\mathrm{Y})$ & $\boldsymbol{C}_{\boldsymbol{o}}(\mathrm{Er})$ & $\boldsymbol{C}_{\infty}(\mathrm{Er})$ & $\boldsymbol{C}_{\boldsymbol{o}}(\mathrm{Yb})$ & $\boldsymbol{C}_{\infty}(\mathrm{Yb})$ \\
\hline 8 & $\mathrm{H}_{2} \mathrm{C}_{2} \mathrm{O}_{4} 0.37$ & 4 & 10 & 8.06 & $<0.01$ & 3.62 & 3.58 & 0.45 & 0.43 & 0.71 & 0.70 \\
14 & $\mathrm{H}_{2} \mathrm{SO}_{4}, 2.5-4$ & 1 & 5 & $<0.01$ & $<0.01$ & 3.58 & 0.03 & 0.43 & $<0.01$ & 0.70 & 0.43 \\
2 & $\mathrm{H}_{2} \mathrm{SO}_{4}, 6$ & 1 & 5 & $<0.01$ & $<0.01$ & 0.03 & $<0.01$ & $<0.01$ & $<0.01$ & 0.43 & $<0.01$ \\
\hline
\end{tabular}

As the experiment shows, in five cycles of stripping with oxalic acid, the iron stripping degree of $96 \%$ and the use of sulphuric acid with a concentration from 2.5 to $6 \mathrm{~mol} / \mathrm{L}$ ensure the complete recovery of yttrium, erbium, and ytterbium.

To determine the effect of iron (3+) on the capacity of D2EHPA with respect to REM, the process of extracting iron (3+) from the organic phase with an oxalic acid solution was studied. During these tests, iron stripping was performed immediately after each stage of REM extraction from WPA.

Iron ion stripping was carried out at a phase ratio of $V_{a q}: V_{\text {org }}=1: 4$, and stirring speed of $450 \mathrm{~min}^{-1}$ for $10 \mathrm{~min}$ by oxalic acid solutions at a concentration of $0.37 \mathrm{~mol} / \mathrm{L}$. Study results are presented in Table 12.

Table 12. Content of iron (3+) and REM in organic phase during stripping process by oxalic acid solution.

\begin{tabular}{ccccc}
\hline \multirow{2}{*}{$\begin{array}{c}\text { Extraction-Stripping Stages Number; } \\
\left(\mathbf{H}_{\mathbf{2}} \mathbf{C}_{\mathbf{2}} \mathbf{O}_{\mathbf{4}} \text { Stripping Agent, 0.37 mol/L) }\right.\end{array}$} & \multicolumn{4}{c}{ Iron and REM Content in Organic Phase, mmol/L } \\
\cline { 2 - 5 } & $\mathbf{F e}$ & $\mathbf{Y}$ & $\mathbf{Y b}$ & $\mathbf{E r}$ \\
\hline 15 stages of extraction-0 stages of stripping & 8.06 & 3.62 & 0.71 & 0.45 \\
15 stages of extraction-14 stages of stripping & 9.63 & 7.43 & 1.57 & 1.14 \\
15 stages of extraction-15 stages of stripping & 0.09 & 7.17 & 1.47 & 1.12 \\
\hline
\end{tabular}

The results obtained show that the treatment of extracts with oxalic acid solutions leads to the effective purification of the organic phase from iron ions (3+) (Table 11; 15 stages of extraction and 15 stage of stripping) and allows the degree of iron (3+) recovery to the aqueous phase of up to $99 \%$ to be acquired. At the same time, the use of oxalic acid after each stage of extraction leads to an increase in the capacity of the extractant for the heavy group of REM by 2-2.5 times due to the removal of iron $(3+)$, which will allow the concentration of REM in the organic phase.

The technological scheme of concentration and separation of the heavy group of REM with their individual carbonate recovery is presented in Figure 6.

Ytterbium extract, obtained from technological WPA by the extraction using a solution of D2EHPA with a volume fraction of 0.3 diluted with kerosene, contains a significant amount of impurities (Table 13). Therefore, the obtained extract is purified from the iron and titanium impurities by the oxalic acid solutions with a concentration of $0.37 \mathrm{~mol} / \mathrm{L}$. The purified extract is treated with sulphuric acid solutions with a concentration of $2-4 \mathrm{~mol} / \mathrm{L}$ for $\mathrm{Y}$ and Er stripping, and $6 \mathrm{~mol} / \mathrm{L}$ for $\mathrm{Yb}$ stripping. Obtaining carbonates of individual REM compounds (in other words, a compounds containing a predominant amount of one rare earth metal) involve the standard operation of precipitation with sodium carbonate and washing the resulting precipitate.

The obtained ytterbium extract with the sum of $\mathrm{Y}, \mathrm{Er}$, and Dy in the second stage of extraction is also sent for purification from impurities. Separation of rare-earth metals on the stripping stage is carried out using sulphuric acid solutions with a concentration of $1-4.5 \mathrm{~mol} / \mathrm{L}$ to obtain two stripped solutions containing both an individual dysprosium compound and a mixture of two metals-yttrium and erbium, the further separation of which involves the use of a countercurrent multi-stage process.

Table 13. Quantitative content of the recovered components in the Yb extract.

\begin{tabular}{lccccccc}
\hline Component & $\mathbf{Y b}$ & $\mathbf{Y}$ & $\mathrm{Er}$ & $\mathbf{F e}$ & $\mathrm{Ti}$ & $\mathrm{Ca}$ & $\mathrm{Si}$ \\
\hline $\mathrm{C}, \mathrm{mmol} / \mathrm{L}$ & 0.71 & 3.62 & 0.45 & 8.06 & 1.61 & $<0.01$ & $<0.01$ \\
\hline
\end{tabular}




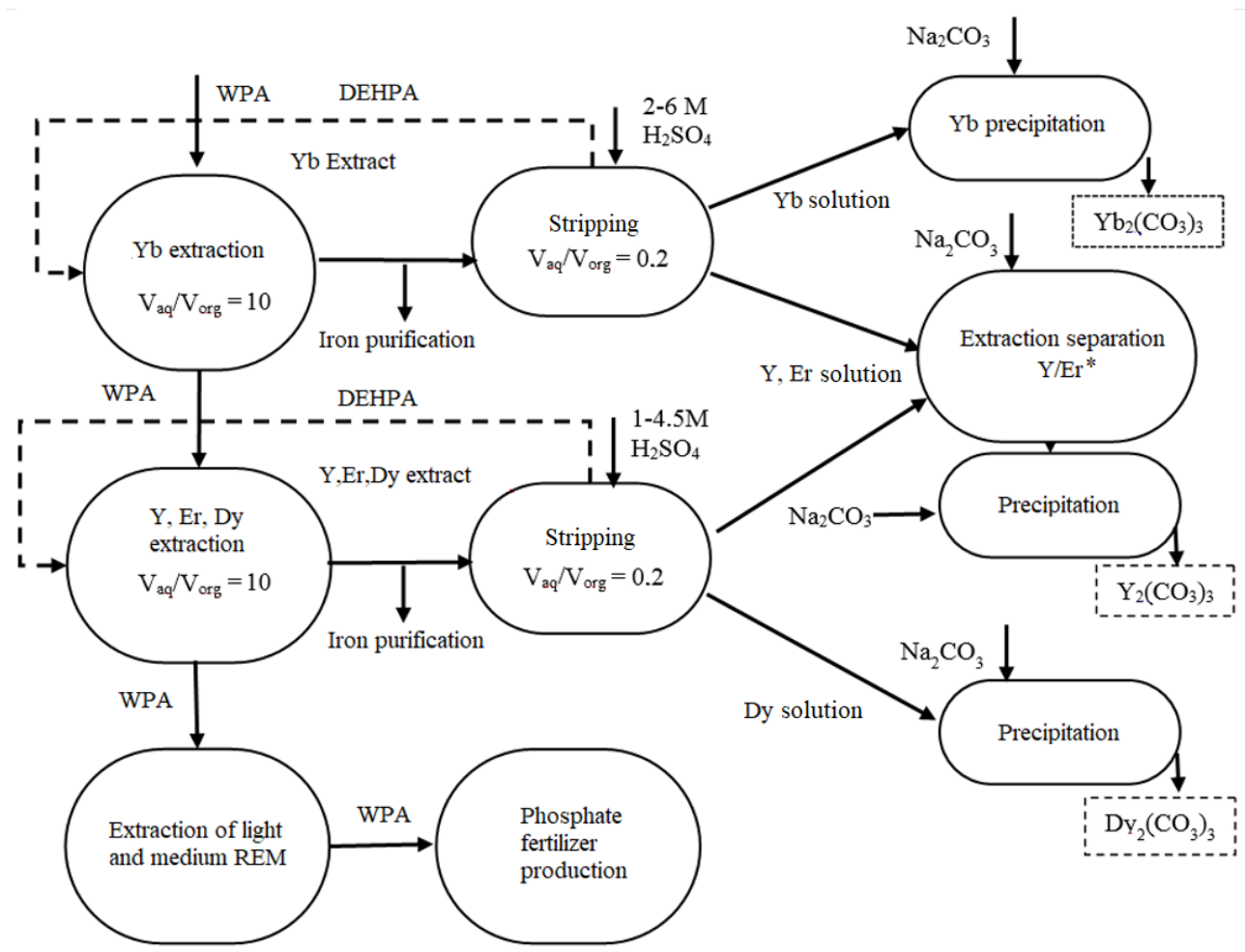

Figure 6. Schematic diagram of the extraction separation of heavy-group REM during processing of phosphoric acid technological solutions. * Stripped solution used in a multi-stage countercurrent separation process of Er and Y.

The results of spectral analysis of the concentrates obtained after precipitation with sodium carbonate according to the separation scheme developed in this work are presented in Figures 7 and 8.

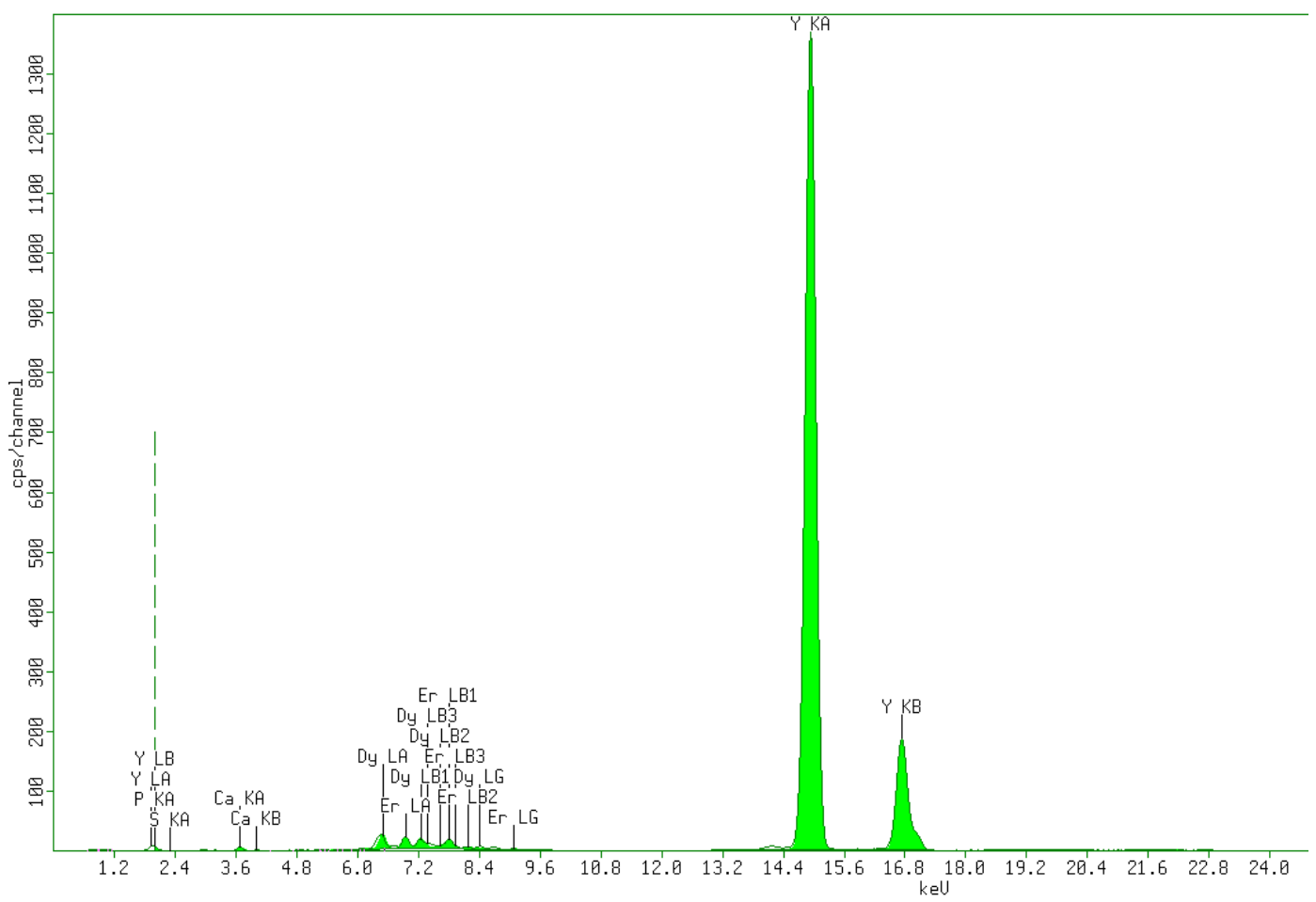

Figure 7. X-ray fluorescence spectrum of yttrium carbonate concentrate obtained from wet-process phosphoric acid (WPA). 


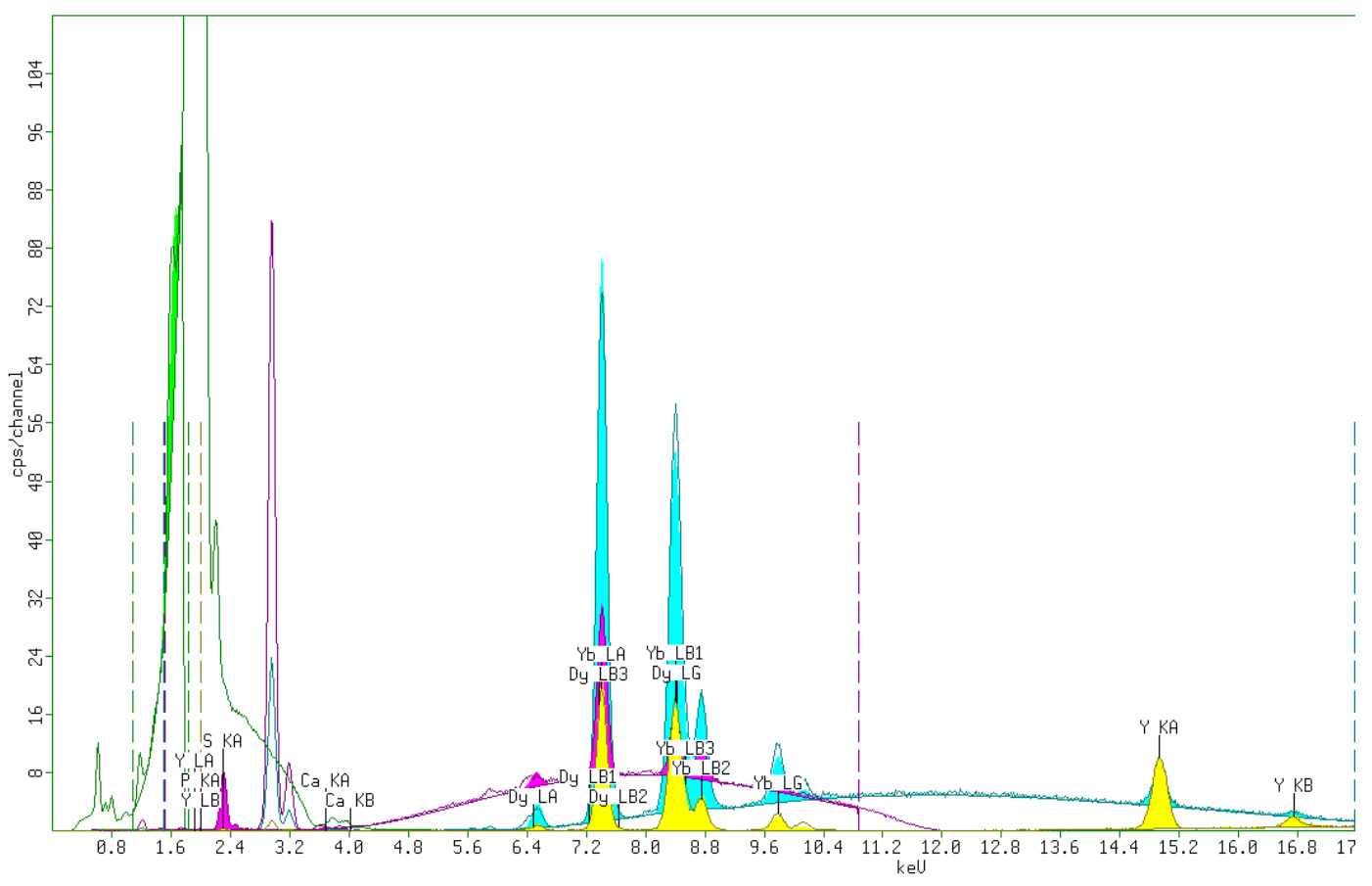

Figure 8. X-ray fluorescence spectrum of ytterbium carbonate concentrate obtained from WPA.

According to the measured spectrum (Figure 7), yttrium concentrate contains up to $95 \%$ of $Y$ and about $5 \%$ of Er and Dy. As impurities, calcium is found with a content of several ppm.

The concentrate of ytterbium carbonate (Figure 6), obtained from WPA solutions, contains up to $83 \%$ of $\mathrm{Yb}$, about $15 \%$ of $\mathrm{Y}$, and about $2 \%$ of Er and Dy, while the Ca content does not exceed several ppm.

\section{Conclusions}

The factors affecting the concentration and separation of heavy REM: Yttrium, ytterbium, erbium, and dysprosium, during their re-extraction from the D2EHPA-based organic phase by sulphuric acid solutions, was determined in this work.

The concentration effect of the $\mathrm{H}_{2} \mathrm{SO}_{4}$ stripping agent on the distribution, concentration, and separation of $\mathrm{Yb}, \mathrm{Er}, \mathrm{Y}$, and Dy was determined. An increase in the content of sulphuric acid increases the stripping degree of each individual REM from the organic phase. The maximum concentration of REM at the stripping stage is achieved by using $\mathrm{H}_{2} \mathrm{SO}_{4}$ solution with a concentration of 4-6 mol/L. Separation factors of rare-earth metals and yttrium reach the following values: $\mathrm{Yb} / \mathrm{Er}=12, \mathrm{Y} / \mathrm{Dy}=9$, $\mathrm{Er} / \mathrm{Y}=2.7, \mathrm{Dy} / \mathrm{Yb}=160, \mathrm{Y} / \mathrm{Yb}=15$, and $\mathrm{Dy} / \mathrm{Er}=18$.

The antagonistic effect of using an additional neutral extractant tributyl phosphate in the organic phase based on D2EHPA on the REM stripping process was revealed. The addition of TBP in an amount of $20 \mathrm{vol} . \%$ led to an increase in the ytterbium extraction degree into the aqueous phase from 60 to $97 \%$, which is obviously due to the formation of organic molecular compounds of the composition n-(D2EHPA).TBP and the preferred transition of inorganic rare-earth acid complexes to the aqueous phase.

The effect of the aqueous and organic phase ratio on the extraction degree of REM was established. With an increase in the aqueous phase volume, and a $V_{a q} / V_{\text {org }}$ ratio above 0.2 , the stripping degree for yttrium and erbium increases to $90 \%$, which is explained by the extraction-stripping equilibrium shift in accordance with the law of mass action.

An increase in temperature leads to an increase in the REM extraction degree into the aqueous phase due to an increase in the solubility of lanthanide sulphates in the aqueous phase and a decrease in the viscosity of the organic phase. 
The choice of the optimal stirring speed of $450 \mathrm{~min}^{-1}$ was determined by the achievement of the maximum values of the REM distribution coefficients into the aqueous phase during the stripping process due to a decrease in the average droplet size of heterogeneous phases and, as a consequence, an increase in the interface surface.

Due to the introduction of an additional stage of purification of the organic phase from iron (3+) with a solution of $\mathrm{H}_{2} \mathrm{C}_{2} \mathrm{O}_{4}$, it was possible to increase the capacity of the extractant for heavy rare-earth metals by $2-2.5$ times and reduce the iron content in the organic phase to $0.9 \%$.

Based on the experimental results, a basic scheme for the separation of rare-earth metals into individual components during WPA processing was proposed, the testing of which made it possible to obtain concentrates of yttrium and ytterbium carbonates with a content of several ppm of impurity components. The developed technical solution can be implemented in an existing cycle of processing apatite concentrates. This development takes into account the shortcomings of existing solutions (listed in Table 14), in particular: It increases the selectivity, does not affect the main technological process, allows the depth of mineral raw material processing to be increased, and reduces the shortage of production of strategic resources.

Table 14. Comparison of reviewed technologies for considered conditions.

\begin{tabular}{|c|c|c|c|c|c|}
\hline Paper & Extractant & $\begin{array}{l}\text { Full Stripping } \\
\text { Acidity, mol/L }\end{array}$ & $\begin{array}{l}\text { Feed Acidity, } \\
\text { mol/L }\end{array}$ & $\begin{array}{l}\text { Fe Co-Extraction } \\
\text { Mitigation }\end{array}$ & Shortcomings \\
\hline Current & DEHPA & $6, \mathrm{H}_{2} \mathrm{SO}_{4}$ & 4.5, $\mathrm{H}_{3} \mathrm{PO}_{4}$ & $\begin{array}{l}\text { Selective removal at } \\
\text { stripping stage }\end{array}$ & $\begin{array}{l}\text { Additional stage of Fe } \\
\text { stripping }\end{array}$ \\
\hline Liu et al. [15] & $\mathrm{P} 507$ + P227 & $3, \mathrm{HCl}$ & $\mathrm{HCl}$ & $\mathrm{N} / \mathrm{A}$ & $\begin{array}{l}\text { The use of expensive } \\
\text { reagents }\end{array}$ \\
\hline Wei et al. [16] & HEHНAP & $4, \mathrm{HCl}$ & $0.03-1.52, \mathrm{HCl}$ & N/A & $\begin{array}{l}\text { Low extraction efficiency } \\
\text { at high-acidic system }\end{array}$ \\
\hline Tunsu et al. [17] & $\begin{array}{c}\text { Cyanex } 923 \\
\text { TODGA } \\
\text { DEHPA } \\
\text { Cyanex } 572\end{array}$ & $\begin{array}{c}0.5 \text { Citric acid } \\
1-6 \mathrm{HCl} \\
1-6 \mathrm{HNO}_{3}\end{array}$ & $\begin{array}{c}1, \mathrm{HNO}_{3} \\
0.4, \mathrm{HCl} \\
1, \mathrm{H}_{2} \mathrm{SO}_{4}\end{array}$ & $\begin{array}{l}\text { Shorting contact time, } \\
\text { Using DEHPA and } \\
\text { Cyanex } 923 \text { mixture }\end{array}$ & $\begin{array}{l}\text { Beneficiation of initial } \\
\text { solutions required }\end{array}$ \\
\hline Gergoric et al. [18] & DEHPA & - & $\begin{array}{l}\text { 1, Citric acid } \\
\text { 1, Acetic acid }\end{array}$ & $\begin{array}{l}\text { High Fe/Nd separation } \\
\text { factor }\end{array}$ & $\begin{array}{c}\text { Separation factors } \\
\text { between REE not defined }\end{array}$ \\
\hline
\end{tabular}

Author Contributions: Conceptualization, O.C.; Methodology, O.C. and V.S.; Software, A.F.; Validation, O.C. and V.S.; Formal analysis, V.S.; Investigation, V.S., A.F. and D.A.; Resources, V.S.; Data curation, O.C. and V.S.; Writing_original draft preparation, V.S.; Writing—review and editing, A.F.; Visualization, A.F. and D.A.; Supervision, V.S.; Project administration, O.C.; Funding acquisition, O.C.

Funding: The work was carried out as part of project No. 19-19-00377 "Technological basis for the extraction and selection of strategically important rare earth elements from apatite products" dated 22th of April, 2019, supported by the Russian Science Foundation in the 2019 competition "Conducting basic scientific research and exploratory research by individual scientific groups".

Acknowledgments: The authors want to acknowledge Tatyana Litvinova and Ivan Zhadovsky for technical support during the $\mathrm{X}$-ray diffraction analysis.

Conflicts of Interest: The authors declare no conflict of interest.

\section{References}

1. Cheremisina, O.V. Extraction of rare-earth metals with di-(2-ethylhexyl) phosphoric acid from phosphoric acid solutions. Zap. Gornogo Inst. 2015, 214, 39-50.

2. Sizyakov, V.M.; Vlasov, A.A.; Bazhin, V.Y. Strategy tasks of the russian metallurgical complex. Tsvetnye Met. 2016, 1, 32-37. [CrossRef]

3. Cheremisina, O.; Sergeev, V.; Fedorov, A.; Iliyna, A. Specific features of solvent extraction of REM from phosphoric acid solutions with DEHPA. Miner. Process. Extr. Metall. 2019, 1-7. [CrossRef]

4. Surampally, R.; Batchu, N.K.; Mannepalli, L.K.; Bontha, R.R. Studies on solvent extraction of Dy(III) and separation possibilities of rare earths using PC-88A from phosphoric acid solutions. J. Taiwan Inst. Chem. Eng. 2012, 43, 839-844. [CrossRef] 
5. Wu, S.; Wang, L.; Zhang, P.; El-Shall, H.; Moudgil, B.; Huang, X.; Zhao, L.; Zhang, L.; Feng, Z. Simultaneous recovery of rare earths and uranium from wet process phosphoric acid using solvent extraction with D2EHPA. Hydrometallurgy 2018, 175, 109-116. [CrossRef]

6. Krea, M.; Khalaf, H. Liquid-liquid extraction of uranium and lanthanides from phosphoric acid using a synergistic DOPPA-TOPO mixture. Hydrometallurgy 2000, 58, 215-225. [CrossRef]

7. Dash, S.; Mohanty, S. ONIOM Study for Selectivity of Extractants for Extraction of Rare-Earth Metals. Chem. Eng. Technol. 2018, 41, 1697-1705. [CrossRef]

8. Wang, L.; Long, Z.; Huang, X.; Yu, Y.; Cui, D.; Zhang, G. Recovery of rare earths from wet-process phosphoric acid. Hydrometallurgy 2010, 101, 41-47. [CrossRef]

9. Dhruva, K.S.; Mallavarapu, A.; Kartikey, K.Y.; Manoj, K.K.; Ravishankar, V.; Harvinderpal, S. Simultaneous recovery of yttrium and uranium using D2EHPA-TBP and DNPPA-TOPO from phosphoric acid. In Proceedings of the Biennial Symposium on Emerging Trends in Separation Science and Technology, Kalpakkam, India, 1-4 March 2010; p. 583.

10. Bontha, R.; Jyothi, R. Rare Earths Extraction, Separation, and Recovery from Phosphoric Acid Media. J. Solvent Extr. Ion Exch. 2016, 34, 226-240.

11. Sergeev, V.V. Ekstrakcionnoe izvlechenie i razdelenie redkozemel'nyh metallov pri pererabotke apatitovogo koncentrata (Solvent Extraction and Separation of Rare Earth Metals in the Processing of Apatite Concentrate). Ph.D. Thesis, St. Petersburg Mining University, St. Petersburg, Russia, 4 July 2016.

12. Liu, Y.; Nam, S.H.; Lee, M. Stripping of Fe(III) from the loaded mixture of D2EHPA and TBP with sulfuric acid containing reducing agents. Bull. Korean Chem. Soc. 2014, 35, 2109-2113. [CrossRef]

13. AKLAGHI, M.; Rashchi, F.; Vahidi, E. Stripping of Fe (III) from D2EHPA using different reagents. In Proceedings of the XXV International Mineral Processing Congress (IMPC), Brisbane, Australia, 6-10 September 2010; pp. 255-262.

14. Jorjani, E.; Shahbazi, M. The production of rare earth elements group via tributyl phosphate extraction and precipitation stripping using oxalic acid. Arab. J. Chem. 2016, 9, 1532-1539. [CrossRef]

15. Liu, T.; Chen, J.; Li, H.; Li, K.; Li, D. Further improvement for separation of heavy rare earths by mixtures of acidic organophosphorus extractants. Hydrometallurgy 2019, 188, 73-80. [CrossRef]

16. Wei, H.; Li, Y.; Kuang, S.; Zhang, Z.; Liao, W. Separation of trivalent rare earths from chloride medium using solvent extraction with heptylaminomethyl phosphonic acid 2-ethylhexyl ester (HEHHAP). Hydrometallurgy 2019, 188, 14-21. [CrossRef]

17. Tunsu, C.; Menard, Y.; Eriksen, D.Ø.; Ekberg, C.; Petranikova, M. Recovery of critical materials from mine tailings: A comparative study of the solvent extraction of rare earths using acidic, solvating and mixed extractant systems. J. Clean. Prod. 2019, 218, 425-437. [CrossRef]

18. Gergoric, M.; Ravaux, C.; Steenari, B.-M.; Espegren, F.; Retegan, T. Leaching and recovery of rare-earth elements from neodymium magnet waste using organic acids. Metals 2018, 8, 721. [CrossRef]

19. Hérès, X.; Blet, V.; Di Natale, P.; Ouaattou, A.; Mazouz, H.; Dhiba, D.; Cuer, F. Selective extraction of rare earth elements from phosphoric acid by ion exchange resins. Metals 2018, 8, 682. [CrossRef]

(C) 2019 by the authors. Licensee MDPI, Basel, Switzerland. This article is an open access article distributed under the terms and conditions of the Creative Commons Attribution (CC BY) license (http://creativecommons.org/licenses/by/4.0/). 